\title{
Facilitating Access to Health Care Through Medical Outreach: Utility and Limits
}

\author{
Ogoh Alubo* \\ Department of Sociology, Nigeria
}

Received: 㘹: October 31, 2018; Published: 眥: November 09, 2018

*Corresponding author: Ogoh Alubo, Department of Sociology, Nigeria

\section{Introduction}

Nigerians almost venerate health care and would stop at nothing to ensure access. Access to health care in Nigeria is, however, problematic for the poor majority. This essay outlines the structure of access, and how the excluded now have some saving grace in the growing phenomenon of medical outreach. There is little question about the utility of medical outreach, but it also has limits. Nigeria runs a plural (western) medical care system which is provided by the government, the missionaries, and the private sector Alubo and Akintunde [1]. These three sources have hospitals, clinics and outposts. Health services in Nigeria are categorized into primary, regarded as the entrepôt, secondary and tertiary facilities. The public sector is the major player in terms of number of facilities and spread Federal Ministry of Health [2], pages 2018-2019. The three sources have different philosophies: the public sector provides health care as part of general welfare, while the private sector has profit motive as the driving force (Itayavyar 1988). The missionaries used medical care for evangelization. The private sector and the missionary sources have run a fee-for service system, while the public sector provided free services until the onset of health sector reforms from the mid-eighties.

\section{Class, Poverty and Access}

It is now known that in most public health care facilities, prescribed drugs have to be procured outside such facilities. There are also crippling shortages of reagents to run tests. Beyond the shortages, the cost of treatment is another challenge to access. According to official documents only an estimated $54 \%$ of Nigerians have access to modern health services. It is also recognized that "rural communities and the urban poor are not well served" (Federal Ministry of Health, 2005: 225). Like many services in capitalist countries, medical care too has a class character. The rich and powerful receive a different type than the poor who are often abandoned to their devices. As the poor struggle to access medical care, the rich and powerful have the option of medical care in exclusive facilities in Nigeria or overseas. The first comprises reserved facilities within public hospitals and highbrow private facilities. More telling are the privileges of highly placed Nigerians who are well positioned to change the health situation in country for the better but seem more concerned with their individual privileges.

This category includes the top civil servants and the last three Presidents. The rich use their own resources and it is simply the question of choice: where and whether to receive medical care in Nigeria, or simply go abroad. For the powerful, it is the question of appropriating public resources for private health needs. As part of privileges for the powerful, President Umaru Yar'ardua went regularly to Germany for the treatment of Pericaditis, (inflammation of the membrane around the heart). He later died in office. Military President Ibrahim Babanigda similarly went to France in 1987 for a condition described as radiculopathy. In 2017, it was the turn of President Muhammadu Buhari, Nigeria's current President since 2015. He first took 50 days to the United Kingdom for some ear related infection and disappeared the second time for 103 days for an undisclosed condition. Privileges of where medical care is obtained extends to the first family. Following a motor bike crash, Yusuf, President Buhari's son, was first treated in Cedacrest Hospital, a highbrow private outfit in Abuja and later flown to West Germany for further treatment (http://saharareporters. com/2018/03/01/yusuf-buhari-returns-nigeria-after-treatment-

It is widely acknowledged that the majority of Nigerians do not get the health care they need. This exclusion relates to issues of distance Haruna-Ogun [3] and cost Alubo [4]. The excluded resort to informal sector of dubious quality and practitioners. The 
poor are routinely either denied treatment or held hostage in both public and private facilities until all bills are paid Alubo [4]. Fearing detention, other patients abscond from wards, when they have recovered sufficiently Fagbemi [5]. In some cases, even corpses (evidence that the treatment failed!) are taken hostage. More disconcerting are cases of new-borns, (with all this implies for campaign for delivery in health facilities) who start life as hostages to Nigeria's system of inequality because their parents are too poor to pay the delivery bills Medical outreach is coming to some rescue. This essay is based on a study of medical outreach missions in central Nigeria in which 15 organizers were interviewed on the philosophy, services provided and challenges [6]. Through outreach services are provided free in designated communities for a short duration of usually 2-5 days.

Outreaches offer mostly primary care with some elements of secondary care; services include treatment for malaria, diarrhea, diabetes and sometimes hernia and other surgeries. The more complex procedures depend on composition of the team (some have few doctors, other have many, including specialists) and access to a functioning theatre. Funded mostly by missionaries, the rich and politicians, medical outreach enables many who are unable to access available care to do so. The huge crowds that turn out in virtually all occasions indicate of the level of exclusion and desperation. Outreaches have no definite plan, all depends on where the funders direct. In virtually all cases, the huge numbers outstrip supplies; there are also problems of durations which are too short to accommodate users. Many turn up on closing days of the missions, forcing them to continue living in frustration. While there is little doubt about its utility, the limits of no definite timetable, short duration and inability to be available when needed are limitations. There are other limits of lack of continuity as outreach is usually a one-off, the people are left in the lurch when they need routine services. Progress in health status and indices, both in general terms or with specific reference to known scourges, cannot be successfully addressed where access remains in favour of the rich and powerful-precisely because it is the excluded majority who will make more difference in morbidity and mortality statistics.

\section{References}

1. Alubo 0 (2018) The Dilemma of Health Access in Nigeria: Notes from Work in Progress. Journal of Yoga and Physiotherapy 3: 5.

2. Federal Ministry of Health (2016) National Health Policy. Abuja Federal Ministry of Health.

3. Haruna Ogun OA (2018) Geographical differentials in uptake of antenatal care services in Nigeria. Health Care Women Int 39(1): 34-49.

4. Alubo 0 (2018) The Dilemma of Health Access in Nigeria: Notes from Work in Progress. Journal of Yoga and Physiotherapy 3: 5.

5. Fagbemi A (2017) Hospitals lament rampant cases of patients absconding during treatment. The Guardian.

6. Alubo SO (2001) The Promise and the Limits of Private Medicine: Health Policy Dilemmas in Nigeria. Health Policy and Plan 16(3): 313-321.
ISSN: 2574-1241

DOI: $10.26717 / B J S T R .2018 .10 .002019$

Ogoh Alubo. Biomed J Sci \& Tech Res

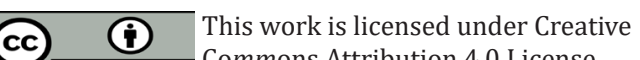

Submission Link: https://biomedres.us/submit-manuscript.php

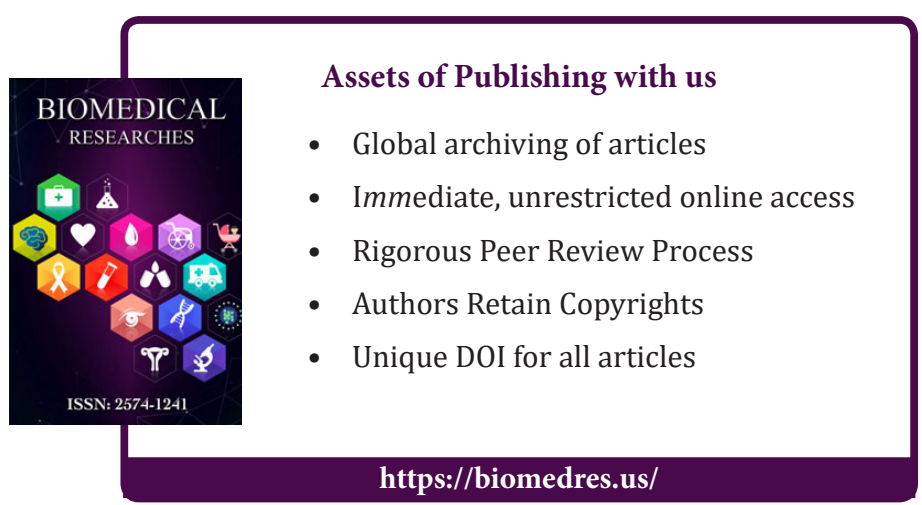

